\title{
Article
}

\section{Predicting Security Incidents in High Secure Male Psychiatric Care}

Ireland, Carol, Ireland, Jane Louise, Jones, Naomi, Chu, Simon and Lewis, Michael

Available at http://clok.uclan.ac.uk/25842/

Ireland, Carol ORCID: 0000-0001-7310-2903, Ireland, Jane Louise ORCID: 0000-0002-5117-5930, Jones, Naomi, Chu, Simon ORCID: 0000-0001-89214942 and Lewis, Michael ORCID: 0000-0001-5567-3569 (2019) Predicting Security Incidents in High Secure Male Psychiatric Care. International Journal of Law and Psychiatry, 64 . pp. 40-52. ISSN 0160-2527

It is advisable to refer to the publisher's version if you intend to cite from the work. http://dx.doi.org/10.1016/j.ijlp.2019.01.004

For more information about UCLan's research in this area go to http://www.uclan.ac.uk/researchgroups/ and search for < name of research Group>.

For information about Research generally at UCLan please go to http://www.uclan.ac.uk/research/

All outputs in CLoK are protected by Intellectual Property Rights law, including Copyright law. Copyright, IPR and Moral Rights for the works on this site are retained by the individual authors and/or other copyright owners. Terms and conditions for use of this material are defined in the policies page.

\section{CLoK}

Central Lancashire online Knowledge www.clok.uclan.ac.uk

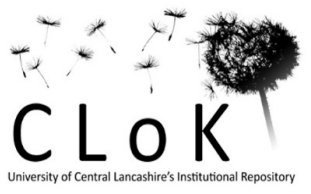


PREDICTING SECURITY INCIDENTS IN HIGH SECURE MALE PSYCHIATRIC CARE

Carol A. Ireland ${ }^{1 *}$, Jane L. Ireland*, Naomi S. Jones, Simon Chu*, Michael Lewis*

School of Psychology, Darwin Building, University of Central Lancashire, Preston, UK, PR1 2HE; *and Ashworth Research Centre, OER Building, Parkbourn, Maghull, Mersey Care NHS Trust, UK, L31 1HW.

To be published in International Journal of Law and Psychiatry.

Purpose

The contribution of environmental and organisational factors in predicting security incidents within a high secure male psychiatric setting is considered using a series of connected studies; a systematic literature review comprising 41 studies and five inquiries (Study 1) to identify core themes of likely importance; application of these themes to incident data through assessment of the ward culture, as perceived by 73 male psychiatric patients and 157 staff (Study 2); and detailed examination of noted relevant factors in the form of interpersonal style, meaningful activity and physical environmental characteristics in a study comprising 62 patients and 151 staff (Study 3). It was predicted that security incidents would be identified through inclusion of environmental and organisational factors.

\footnotetext{
${ }^{1}$ Corresponding author. Email: CAIreland@uclan.ac.uk; University of Central Lancashire, Preston, UK, PR1 2HE; Tel: +44 (0)1772 201201.
} 
Results

The systematic review demonstrated the importance of accounting for staff characteristics, patient interactions, physical environment and meaningful activity. The subsequent study noted the importance of only specific aspects of the social environment, with the final study demonstrating that incidents were associated with controlling interpersonal styles of staff, lower perceived fairness, and less involvement in off-ward activities. Perception of fair treatment and off-ward activities mediated the staff interpersonal style and security incident relationship.

Conclusions

The research proposes a preliminary framework - the McKenna Framework for understanding Incidents in Secure Settings (M-FISS) - to explain the occurrence of security incidents in secure psychiatric care.

KEY WORDS: Secure incidents; High Secure Psychiatric; McKenna Framework. 


\section{PREDICTING SECURITY INCIDENTS IN HIGH SECURE MALE PSYCHIATRIC CARE}

\section{Introduction}

'Security incident' is broadly defined to cover a range of behaviours within secure forensic hospitals, such as harm to others, escape incidents and rule breaking (Department of Health, 2010). The number of incidents in high secure settings is recognised as high, with Uppal and McMurran (2009) noting over 5,000 incidents occurring in a single year in one high secure male hospital in the UK, $30 \%$ of which were physical and/or verbal incidents. Public inquiries into major security incidents in high secure settings, such as harm to others on a broad scale and/or loss of organisational control (e.g. Blom-Cooper, Brown, Dolan \& Murphy, 1992, Fallon, Bluglass, Edwards \& Daniels, 1999), have emphasised culture and environment as important facilitating factors. It has been further argued that challenges occur as staff try to sustain the balance between providing a therapeutic climate and maintaining sufficient levels of security (Hodge \& Renwick, 2002).

Maintaining security is an integral aspect of secure care, captured best through three domains: physical, procedural and relational (Collins \& Davies, 2005). Physical and procedural refers to security that can be easily observed, such as fences, locks, patient searches and item restrictions; whereas relational security refers to the richness of knowledge that staff have about patients and how to manage their behaviour (Collins \& Davies, 2005). The more relational aspects of security have received little attention when understanding security incidents (Exworthy \& Gunn, 2003; Tighe \& Gudjonnson, 2012), although their value is recognised (Collins \& Davies, 2005). This is surprising when considering how a primary aspect of relational security is ensuring positive, supportive relationships between patients and staff (Department of Health, 2010), and creation of a positive ward culture (DoH, 2010; Tighe \& Gudjonsson, 2012). Supportive relationships between residents and staff are associated with 
fewer incidents (Chaplin, McGeorge \& Lelliott, 2006; Gadon, Johnstone \& Cooke, 2006; van der Helm et al, 2012), with perceptions of unfair treatment linked to higher levels of indiscipline in settings such as prisons (Reisig \& Mesko, 2009). This has not been examined, however, in high secure psychiatric settings and neither has there been a focus on the full range of potential incidents.

Whilst there is acknowledgment of high secure psychiatric units presenting with elevated levels of incidents, and a potential association between security incidents that attends to the more relational elements, little attention has been devoted to understanding how such incidents can be predicted. There are theories and models that can be drawn upon to explain how indiscipline can occur within closed settings. Importation theory, for example, views indiscipline in secure settings (i.e. prisons) as a result of the characteristics an individual brings with them into the environment. This includes attitudes and beliefs that encourage engagement in prison misconduct (Thomas \& Foster, 1973; Poole \& Regoli, 1983), and a history of violence, drug use and a diagnosis of psychosis in secure psychiatric settings (Dack et al, 2013; Godelieve de Vries et al, 2016; Stewart \& Bowers, 2013; Stone et al, 2011; Williamson et al, 2013). Although importation factors have been found to predict misconduct, they cannot provide a complete understanding of incidents, nor do they predict all incidents (Walters \& Crawford, 2013) and consider environmental factors.

Deprivation theory tries to address this by considering the role of the [prison] environment as the main reason for misconduct (Sykes, 1958; Irwin \& Cressey, 1962). Here, prison existence is considered so oppressive and degrading that prisoners act out in response. Opportunities for stress in prison are numerous and include crowding and a lack of activities (Wortley, 2002). Deprivation factors have been referred to as the 'pains of imprisonment' and include lack of freedom, autonomy, goods, services, and intimate relationships (Sykes, 1958). 
They have also been extended to cover boredom due to lack of activities, and feeling unsafe, both of which are related to increased levels of misconduct (Rocheleau, 2013). In secure forensic psychiatric settings, the theory applies equally, with crowding, lack of activities, and negative interactions with patients and staff linked to adverse incidents (Chaplin et al, 2006; Hallet et al, 2014; Meehan et al, 2006; Pulsford et al, 2013; Soares et al, 2000; Virtanen et al, 2011). Even when controlling for importation factors, deprivation factors have been found to have an effect on prisoner behaviour (van der Laan \& Eichelscheim, 2013), thus highlighting the importance of more dynamic and environmental factors.

Importation and deprivation factors can only provide a partial understanding of what raises the risk for incidents to occur; they are also often considered in isolation and not integrated into a single theory to capture a fuller range of elements, such as interacting factors and interpersonal dynamics, in detail. General Strain Theory (Agnew, 2001) attempts to identify a more complete understanding of the challenges, and its value in explaining prison misconduct beyond a simple application of importation and deprivation is increasingly being recognised. In attempting to integrate both elements, it recognises that the environment (deprivation) can cause misconduct, yetimportation factors, such as antisocial values, may increase the likelihood of misconduct when the environmental factors are present (Blevins, Listwan, Cullen \& Johnson, 2010). It argues that individuals use delinquency (i.e. misconduct) to cope with negative relationships and experiences (Morris et al, 2012). It identifies a range of 'strains', such as negative stimuli (e.g. high noise levels), and removal of both positive stimuli (i.e. autonomy and privacy), and goal acquisition (Agnew, 1992), leading to feelings of disappointment, fear, anger and frustration (Agnew, 2001). The chronic nature of this strain (Blevins et al, 2010) is recognised as a further element that impacts negatively on an ability to cope with strain, which then influences responding. 
Although identifying the potential strains and considering the interacting element of importation and deprivation factors, General Strain Theory does not present an outline as to why some of these strains may be particularly important to account for. To consider this, it is important to focus briefly on the forensic application of motivational and self-determination theory (Deci \& Ryan, 2000), namely the Good Lives Model (Ward \& Gannon, 2006) to understand why some strains become so important to the extent that they promote misconduct.

The Good Lives Model states that all individuals have core needs, referred to as primary goods. These include life (including healthy living), acquiring knowledge, achieving excellence in work and recreation, agency, finding inner peace, acquiring relatedness with others, being part of a community, experiencing spirituality, pleasure and creativity. It is argued, via this model, that some will use dissocial behaviour to try and meet these needs (Fortune, Ward \& Polaschek, 2014).

Similarities are clear between the primary goods of the Good Lives Model and different types of strain. For example, the primary good of excellence in agency seems to relate to the strain of experiencing a lack of autonomy and privacy; with the need to experience relatedness disrupted by forced interactions with others and the challenges that are associated with this. It could be speculated that the environment prevents a stress-free acquisition of these goods, with dissocial behaviour used instead to acquire them. Although untested in secure settings, it is accepted that the environment is key in the positive acquisition of these primary goods (Deci \& Ryan, 2000), and an environment with considerable strains could be expected to disrupt this. Indeed, environments that are controlling and rejecting of an individual's needs can lead to displays of defensive behaviours and psychological withdrawal (Ryan, Deci \& Grolnick, 1995). 
A consistent theme that is thus emerging is the role of engagement with others, how this is acquired and/or perceived, and what can cause this to become strained and lead to misconduct. Legitimacy of authority is a factor of particular value to consider. It refers to prisoners accepting prison authority even if they do not agree with the restrictions placed upon them (Jackson et al, 2010). If prisoners do not see the regime or prison officers as legitimate, a higher level of force is required to maintain control, leading to increased rule breaking (Jackson et al, 2010). The perception of fairness or procedural justice is a noted component of legitimacy, with procedural justice being the notion that rules and processes used to resolve disputes are fair and just (Tyler, 2006). If rules are perceived unfair then the legitimacy of the authority dictating these is lessened and individuals are less likely to follow them (Tyler, 2006). This is supported by Reisig and Mesko (2009) who found that prisoners who believed prison officer's use of authority as procedurally fair were less likely to report engaging in misconduct and were charged with violating fewer institutional rules.

However, it is not simply perception of fairness and procedural justice; the interpersonal style of patients and staff is also important in accounting for misconduct. Kiesler (1987) described interpersonal style as having two dimensions: power and affiliation. An individual's interpersonal style on the power dimension can range from dominance to submission, whereas on the affiliation dimension it can range from hostility to friendliness. Interpersonal behaviours are expected to induce reactions in others (Daffern, Day \& Cookson, 2012), with this termed complementarity (Lillie, 2007). According to complementarity, behaviours on the affiliation dimension will prompt a matched reaction (e.g. friendliness producing friendliness). Behaviours on the control dimension, however, are likely to evoke the opposite response (e.g. dominance leading to submission). 
Interpersonal style and complementarity, perceptions of legitimacy and a drive to seek primary goods, are all concepts of potential relevance to understanding security incidents. They have not, however, received attention when trying to consider why security incidents take place in secure psychiatric settings, nor have they been considered alongside the seminal theories of Importation, Deprivation or General Strain Theory. What has become evident is a need to advance current understanding of security incidents by considering how factors can be captured and integrated in a manner that enhances our understanding of security incidents in high secure settings.

The current research aims to address this through three joined studies exploring physical and environmental factors and their role in predicting security incidents in high secure psychiatric care. It will result in the proposal of an integrated framework that could be used to describe the emergence of security incidents. Comprising of a systematic literature review of environmental factors and two empirical studies, conducted in a high secure male psychiatric setting, it is predicted that:

1.) As indicated by General Strain Theory and The Good Lives Model, security incidents will be predicted by indicators of strain and barriers to having primary needs met.

2.) The physical environment will be associated with the number of security incidents.

3.) Negative interpersonal staff styles, namely those characterised by hostility and dominance, will predict increased numbers of security incidents.

4.) Perceived unfairness will be associated with increased levels of security incidents. 
Study 1: Exploring the environment: A systematic review

\section{Method}

The Preferred Reporting Items for Systematic Reviews and Meta-Analyses guidelines (PRISMA; Moher et al, 2009) were adhered to, with the review comprising both published studies and inquiries. Search terms were developed to answer the research questions using key words from the TILT tool (Tilt, Perry \& Martin, 2000), an assessment used in secure psychiatric care to record security incidents. This includes information such as whether the resident has a history of behaviours, for example, assault, rule breaking, substance use and protests. There were 25 search terms in total, and too extensive to repeat in full here, but they included: culture, atmosphere, environment, security, incident and misconduct.

Research was identified via PsychINFO, PsychArticles, Web of Science and Scopus databases. Relevant unpublished research was searched for using CLok and EThoS systems. Full text articles were retrieved if they satisfied the following inclusion criteria: 1.) assessed the impact of cultural, environmental or security factors on one or more security incidents; 2. ) used in-patient psychiatric, forensic psychiatric or prison populations; and 3) were deemed to have an appropriate level of quality. Reports from government inquiries were included if they: 1.) investigated a security incident at a high secure hospital or prison; and 2.) provided an examination of security factors in secure services. 
3. Results

The full presentation of this study in regard to PRISMA is outside the scope of this multi-study paper, and so only a brief summary is noted here. Yet, a flow diagram summarising the papers included and excluded at each stage of the search process as per PRISMA is noted in Figure 1.

$<$ Insert Figure 1 here>

A total of 7,062 article hits were returned, with removal of duplicates resulting in 6,902 articles. These were then screened for relevance based on titles and abstracts, with attention to the study selection criteria. This resulted in 43 papers being included, with six papers excluded when the full text was considered; four did not assess the impact of relevant factors on security incidents and two were literature review articles without a systematic method. When searching reference lists, four further studies were identified as potentially relevant. These were screened for eligibility and included in the final sample. This resulted in a total of 41 studies in the review. Six inquiry reports were initially considered appropriate for this review, one that was later excluded for being a description of events rather than an inquiry.

\subsection{Study characteristics}

All inquiry reports included were undertaken in high secure psychiatric services in the UK, with no reports relating to prisons. Reviewed studies were based in in-patient psychiatric facilities $(n=24)$ and prisons $(n=15)$. Two studies used both psychiatric and prison samples. Thirty-eight of the studies were based in adult facilities. 


\subsection{Thematic analysis}

This stage of analysis was completed using a method of thematic analysis outlined by Thomas and Harden (2008) where the main results of each paper is line coded and then these codes are organised into related themes. Two independent researchers who were blind to the aims of the study confirmed that the themes identified were the best fit for the data. None of the content of the themes was changed as a result of this process. Five main themes were identified in the literature that related to an increase in security incidents:

\subsection{Theme 1: Negative staff characteristics}

The way that staff behaved in front of patients or prisoners was seen as a trigger for incidents. This theme was split into two subthemes; lack of knowledge and experience in staff and staff failure to value patients and show respect. Lack of knowledge and experience in staff was related to staff factors such as a lack of knowledge about the theory behind the care being given, about individual patients and about mental illness (Bowers et al, 2006; Hallet et al, 2014; Muir-Cochrane, Baird \& McCann 2015). Staff failure to value patients and show respect appeared linked to increases in security incidents, such as aggression. Residents, for example, believed that staff members' negative attitudes were a major factor in the lead up to violence (Bowers et al, 2006; Hallet et al, 2014).

\subsection{Theme 2: Negative interactions with others}

This theme focused on interactions with staff and other residents. Two sub-themes were identified; lack of quality support from others, and perceived provocation from others. Lack of quality support from others focused on limitations in quality support from staff and other 
residents, increasing levels of security incidents. Staff taking time to interact with patients informally, for example, were identified as a preventative approach to aggressive incidents (Francis et al, 2009; Hallet et al, 2014). Perceived provocation from others was identified as an antecedent to security incidents, with provocation generated from other residents, staff or visitors (Johnson et al, 1997; Powell, Caan \& Crowe, 1994; Pulsford et al, 2013).

\subsection{Theme 3: Inadequate physical environment}

The physical environment was considered to impact on the number of incidents. It included crowding, lack of privacy and personal space and sub-optimal architecture as subthemes. Crowding related to how higher resident numbers had an effect on incident numbers, with higher levels of crowding associated with violent and non-violent incidents (Steiner \& Wooldredge, 2009; Virtanen, 2011). Lack of privacy and personal space was distinct from the sub-theme crowding, as it related to the actual amount of space a person has, rather than the number of prisoners on a wing. A lack of personal space has been perceived by patients as an incident antecedent (Hallet et al, 2014; Johnson et al, 1997; Meehan et al, 2006). Sub-optimal architecture referred to reductions in violent incidents noted when residents were moved to facilities characterised as having large outdoor areas, large windows and a greater amount of light (Olver et al, 2009).

\subsection{Theme 4: Overly restrictive environment}

Policies and procedures deemed overly restrictive were considered antecedents to aggression (Bidna, 1975; Duxbury, 2002; Johnson et al, 1997; Powell, Caan \& Crowe, 1994). As levels of restriction and control decreased, so did incidents of violence (Urheim et al, 2011). In addition, the inconsistent and inflexible application of the rules on the wards was an 
important factor in increasing security incidents (Finnema, Dassen \& Halfens, 1994; Hallet, Huber \& Dickens, 2014).

\subsection{Theme 5: Lack of consistent and meaningful recreation}

The lack of consistent and meaningful recreation for patients was considered to increase security incidents. This related in particular to recreational activity, such as exercise and hobbies, that took place away from the patients' ward (termed off-ward activity). A lack of meaningful activities was identified as a source of frustration for patients, with this thought to lead to aggressive incidents (Francis et al, 2009; Meehan, McIntosh \& Bergen, 2006).

\section{Discussion}

Themes were identified from the systematic review that were in keeping with the expectations of Deprivation and General Strain Theory. Crowding, lack of (meaningful) activities, negative interpersonal reactions (Chaplin et al, 2006; Hallet et al, 2014; Meehan et al, 2006; Pulsford et al, 2013; Rocheleau, 2013, Soares et al, 2000; Virtanen et al, 2011, Wortley, 2002) were identified, although focus was less on the interaction between individual and environmental factors, with a greater apparent emphasis on environmental drivers for security incidents. This appeared more consistent with Deprivation Theory, although there was a notable absence of explaining how these elements impacted on individuals. Thus, any direct consideration of General Strain Theory appeared less evidenced, although speculation on their negative impacts is not unreasonable.

In addition, there was a noted inclusion of the importance of interpersonal interactions, application of procedures by staff, staff attitudes, and the wider aspects of the physical 
environment. Regarding interpersonal interactions with others, these were found to focus on negative interactions with others in the form of provocation and poor quality support. The further identified theme of staff characteristics was, consequently, unsurprising since it could be expected to link with the theme of poor quality support. It certainly highlighted how, in terms of Importation Theory (Thomas \& Foster, 1973; Poole \& Regoli, 1983), that it was staff (negative) characteristics that were potentially the imported elements into the environment, with the literature silent on resident imported factors. This would appear to present with a novel view of Importation Theory than that captured in the literature

As noted, this is all directing attention to the role of the environment and its many facets, including a closer attention to the physical environment, such as space, light and openness. The missing element, however, in drawing conclusions represents a closer examination of staff and patient views regarding not just the factors of importance, but why they are important. It is clear that many of the factors identified are consistent with primary goods/needs, such as community, autonomy, relatedness, meaningful recreation, etc., as we would expect when considering the Good Lives Model (Ward \& Gannon, 2006). Nevertheless, actual examination of potential challenges would allow for further consideration of the full range of potential goods not being met within the environment, any potential application of General Strain Theory (Morris et al, 2012) and identification of the value, or not, of Importation Theory. Currently there appears a stronger impression from the literature of the value of Deprivation Theory. To explore the environment, interpersonal relationships and staff engagement, and existence of primary goods in more detail, the ensuing study was conducted to allow for an incorporation of both staff and resident views. Specifically, it aimed to examine the association between ward culture factors and incidents in a high secure service. It was hypothesised that: 
1. Wards at the hospital will have differences in perceptions of ward culture;

2. Wards with more positive cultures (measured as having a more enabling environment and higher levels of relational security) will have fewer numbers of aggressive and nonaggressive incidents

Study 2: Association between ward culture and incidents in high secure psychiatric services

\section{Method}

\subsection{Participants}

Participants were recruited from wards at a high secure forensic psychiatric facility in the UK. Four hundred and twenty-seven ward staff were identified as eligible to take part. Staff members were deemed eligible if they worked on one of the wards and had a good knowledge of its environment. This meant that staff participation was mainly restricted to ward nurses. Of these, 157 agreed to complete questionnaires.

One hundred and ninety-six patients were identified as potential participants, with seventy-three consenting to take part. Patients were deemed eligible if their responsible clinician had provided confirmation that they were able to consent to and engage with the research. As all measures were written in English, it was essential that patients were able to speak English. The overall response rate was $37 \%$.

All patient participants were male. Seventy-two (46\%) staff participants were male. Most of the sample described themselves as White British (86\%), with 13\% identified as Black Caribbean and $1 \%$ as White Irish. The sample ranged from 21 to 60 years of age. 


\subsection{Measures}

All participants completed the following measures, with the wording adapted slightly to suit the population (staff/patient):

Essen Climate Evaluation Schema (EssenCES; Schalast et al, 2008), a 15-item scale that measures three aspects of ward environment: Therapeutic hold (i.e. extent to which the environment is supportive of a patient's needs); Experienced safety (i.e. extent to which there is tension and a threat of aggression or violence on the ward); and Patients' cohesion and mutual support (i.e. extent to which patients supported one another). An example question is, "there is good support among patients".

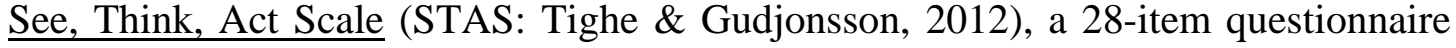
based on UK National Health Service, See, Think, Act guidelines (STA; DoH, 2010). It included questions regarding the therapeutic management of risk, pro-social team culture, boundaries and patient focus. An example question was, "we understand why maintaining a clear boundary with patients is important".

Enabling Environments questionnaire, adapted from the standards used to assess facilities for an Enabling Environments award. This is a quality mark given by the UK Royal College of Psychiatrists to effective, therapeutic environments. The questionnaire comprises 25-items relating to the areas of relationships, behaviour, activities and support on the ward, such as, "I feel supported by those in authority".

In addition, incident data was collected from the electronic patient recording system. Incidents were collected for six months using a data collection sheet designed by the lead researcher, and information was collected about the month, time of day, ward location, type of incident, incident details and number of patients and staff involved in the incidents. The 
incidents were restricted to threats, inappropriate behaviour, substance use (e.g. misusing medication) and trading.

\subsection{Procedure}

This study was granted ethical approval from the Health Research Authority and the University of Central Lancashire, UK. Ward environment data was collected from 13 wards, both high and low dependency (dependency relates to the level of support that a patient requires). Staff were given a consent form and, if they agreed to take part, given questionnaire booklets to complete. Questionnaires were completed by all staff participants individually.

Potential patient participants were only approached once consent had been obtained from their Responsible Clinician. If they agreed, a consent form was signed. The researcher would then sit with the patient in a separate room whilst the patient completed the questionnaire. Incident data was collected covering the six-month period preceding data collection.

\section{Results}

Data was first screened for missing data, which was limited with no data above $0.5 \%$ missing for any variable. Little's MCAR test indicated that any missing data was missing at random $\left(\mathrm{X}^{2}(1859)=1744.72, \mathrm{p}=0.97\right)$. Expectation Maximisation was used to estimate missing data. No multivariate outliers were found. Extreme univariate outliers were altered to make their scores less extreme. Principal components analysis was used to extract factors from the Enabling Environments Questionnaire and the See Think Act Scale (Kaiser-Meyer-Olkin Measure of Sampling Adequacy $=0.82$; Bartlett's Test of Sphericity, $\mathrm{p}<0.001$ ). Items from 
these questionnaires were then analysed jointly due to some overlap in factors measured. Two factors were extracted. The first factor was named relational security $(\alpha=.88)$ and covered risk, boundaries and understanding which factors of the environment may have an impact on patient wellbeing. The second was named service involvement $(\alpha=.77)$ and included items that detailed being included in decision-making and the planning of personal development. Regarding the EssenCES, the alpha for patient cohesion was poor $(\alpha=0.59)$. Howells et al. (2009) suggested the removal of the item "most patients don't care about their fellow patients' problems" in order to improve reliability for this scale. This did improve reliability in the current study ( $\alpha=0.63)$. The therapeutic hold scale was also poor in terms of reliability ( $\alpha=$ 0.59) but not particularly so considering the number of items $(\mathrm{n}=5)$, with all item-to-total correlations positive. However, the experienced safety scale was dropped from analysis; as well as having weak reliability $(\alpha=.42)$, three items correlated poorly with the scale (CITC $<0.20)$. Table 1 presents the mean scores and standard deviations for all variables.

<Insert Table 1 here>

A series of one way ANOVAs indicated that patients perceived higher levels of relational security on wards than $\operatorname{staff}(\mathrm{F}(1,224)=61.64, \mathrm{p}<0.001)$. Patients also had higher scores than staff for a perception of patient cohesion $(\mathrm{F}(1,224)=5.68, \mathrm{p}=0.02)$, indicating that patients believed their relationships with other patients to be more supportive than staff perceived them to be. However, staff perceived themselves to have higher levels of involvement in the service than patients $(\mathrm{F}(1,224)=9.10, \mathrm{p}=0.003)$. Staff also perceived higher levels of therapeutic hold (that is, the extent to which the environment is supportive of a patient's needs) $(\mathrm{F}(1,170)$ 
$=4.77, \mathrm{p}=0.05)$, indicating that they believed their relationships with patients to be more positive than patients did.

Patients and staff on higher dependency wards perceived less patient cohesion ( $\mathrm{F}(1$, $224)=3.93, p=0.05)$ and more therapeutic hold than those on lower dependency wards $(\mathrm{F}(1$, 217.50) $=10.30, p=0.003)$, suggesting less cohesion within the patient groups on high dependency, yet higher dependency wards are perceived to be more supportive in regard to therapeutic hold As such, the staff-patient relationships on these wards were perceived to be more positive than on low dependency wards. No significant differences were found between wards for relational security $(\mathrm{F}(1,224)=0.20, \mathrm{p}=0.66)$ or service involvement $(\mathrm{F}(1,224)=$ $0.49, \mathrm{p}=0.48)$.

Correlations were conducted to investigate whether there was an association between the number of ward incidents and scores on relational security, service involvement, therapeutic hold and patient cohesion scales. No significant correlations were found across incidents (all $\mathrm{r}=<-0.45)$.

Associations emerged when incidents were considered by type, restricted to threats, inappropriate behaviour, substance use and trading. There was a moderate negative correlation between the number of threats made and patient cohesion $(r=-0.56, p=0.05)$, indicating that lower levels of patient cohesion associated with an increased number of threats. A negative correlation was also found between the number of threats and patient perceptions of therapeutic hold $(\mathrm{r}=-0.61, \mathrm{p}=0.03)$, indicating that lower levels of therapeutic hold were linked to increased threats. A moderate negative correlation was found between what was classified as 'inappropriate behaviour' (i.e. sexual disinhibition, boundary testing and refusal of staff requests) and patient perception of service involvement $(r=-0.58, p=0.04)$, suggesting there are more incidents of inappropriate behaviour when patients feel less involved in the service. 
Strong negative correlations were found between substance incidents and staff perception of patient cohesion $(\mathrm{r}=-0.64, \mathrm{p}=0.02)$, indicating that a higher number of incidents involving substances were related to lower cohesion between patients (as viewed by staff). Further, a strong positive correlation was found between the number of incidents of trading and perception of service involvement by staff $(r=0.66, p=0.02)$, indicating that a high number of trading incidents occur on wards where the staff felt more involved in the service.

To consider further the relationship noted in relation to threats and inappropriate behaviour, two multiple regression analyses were conducted to explore the factors that contributed to these incidents in more detail. The regression model for threats was significant as a multivariate effect $(\mathrm{F}(2,10)=5.40, \mathrm{p}=0.03)$, but the individual coefficients were not significant $(\mathrm{PC}(\mathrm{p}=0.17)$; TH $(\mathrm{p}=0.09))$; neither patient cohesion or therapeutic hold significantly contributed. For inappropriate behaviour, patient perception of service involvement and staff perception of therapeutic hold significantly improved the ability to predict inappropriate behaviours $(\mathrm{F}(2,10)=5.25, \mathrm{p}=0.03)$. Patient perception of service involvement was shown to be a significant predictor $($ Beta $=-0.47, \mathrm{p}=0.05)$, whereas staff perception of therapeutic hold was not $($ Beta $=0.44, \mathrm{p}=0.07)$.

\section{Discussion}

The current study demonstrated an association with specific aspects of the social environment and incidents, further noting the importance of accounting for different types of incidents as opposed to considering them as a homogenous variable. Lower levels of patient cohesion and therapeutic hold were individually associated with an increased number of threats. Staff reports of lower levels of patient cohesion were also associated with increased 
substance incidents. More incidents of inappropriate behaviour were associated with patients feeling less involved in the service, with more trading incidents associated with increased staff involvement in the service. Differences were also noted across environments, with patientstaff relationships and therapeutic hold improving on higher dependency wards, with patient cohesion lower.

Overall, it would appear that there are specific aspects of the social environment that are worthy of accounting for, particularly in relation to the cohesive nature of the patient group and the extent to which the environment fulfils needs (i.e. therapeutic hold and involvement in the service). Involvement in the service is particularly interesting in that it associates with the concept of autonomy and need for some degree of mastery over the environment. In this sense, it fits with the expectations of the Good Lives Model and, speculatively, could suggest that challenges to this link to increased indiscipline (Fortune, Ward \& Polaschek, 2014). In addition, the finding that increased threats were associated with lower scores on patient cohesion and therapeutic hold suggests that wards categorised by a lack of supportive and respectful relationships have a higher number of threat incidents. This is consistent with research that indicates relationships with others are important in managing the risk of incidents (e.g. Duxbury \& Whittington, 2005; Finnema, Dassen \& Halfens, 1994), with supportive and respectful relationships known to increase perceptions of fairness, thus resulting in improved behaviour (Jackson et al, 2010).

However, the lack of association with overall incidents is not consistent with research that has argued for 'ward culture', including relationships, to be associated with incidents (e.g. Chaplin, McGeorge \& Lelliott, 2006; Duxbury, 2002). The current study indicates that associations are more specific and dependent on the nature of the incidents. The lack of overall significance, however, would seem to conflict with General Strain Theory and specifically the 
argument that cultural factors represent forms of strain, and that individuals engage in negative behaviours as they are unable to cope with this strain (Agnew, 2001; Blevins et al, 2010; Morris et al, 2012). This is, however, speculative since the results do indicate evidence of disparity between patients and staff with regards to how they viewed relational security, patient cohesion and therapeutic hold in particular. Whereas this is arguably to be expected, considering that they are two different groups, nevertheless provides a clearer indication of the perceived differences between these populations effectively residing in the same environment. What is not yet known is the role of this reported disparity in promoting incidents; it could be suggested that marked disparity could promote strain. The disparity also indicates the importance of considering Importation Theory more along the lines of what patients and staff each bring with them individually to the setting.

The current study is limited by its focus on patient and staff perceptions across a restricted set of environmental variables, failing to account for objective factors that could be associated with incidents and for interpersonal variables, including self-reported incidents of aggression. It does provide an indication that environmental variables linked to interpersonal factors are worthy of further consideration (e.g. cohesion) but does not explore how interpersonal variables may promote incidents and what specific components are important. Thus, the current study has indicated that although the social environment, notably the less positive aspects (e.g. less autonomy/service involvement, needs not being met by the environment, poor cohesion), are related to incidents, the associations are limited and cannot account for what promotes factors likely associated with increased incidents. This is the function of the next study, which aims to examine interpersonal factors in more detail, extending it to cover physical aspects of the environment, as identified in the systematic review, in an effort to understand where the core variables could lie. 
Study 3: The relationship between interpersonal style, meaningful activity, the physical environment and security incidents

\section{8. $\quad$ Method}

\subsection{Participants}

Four hundred and twenty-five members of staff were identified as being eligible to take part. Of these, 151 completed questionnaires (61\% male, 39\% female). One hundred and ninety-one patients were identified as potential participants, with 62 taking part. This resulted in an overall response rate of $35 \%$. All participants were recruited from a high secure forensic psychiatric facility. All patient participants were male. Most of the sample described themselves as White British (91\%) and ranged from 23 to 59 years of age.

\subsection{Measures}

All participants completed the following:

$\underline{\text { Impact Message Inventory - Circumplex }}$ (IMI-C; Brief Version; Kiesler \& Schmidt, 2006): This 28 -item scale measuring feelings relating to interpersonal behaviour. It measures four types of interpersonal style: dominant, submissive, friendly and hostile, with a patient and staff version. In the patient version, questions are asked about how staff make them feel about themselves. An example question would be "when I am with members of staff they typically make me feel that I could lean on them for support".

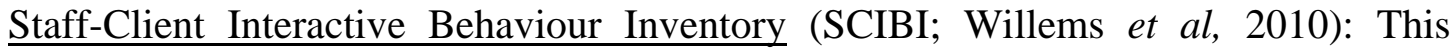
identifies ways that staff interact with patients, based on their interpersonal style. The 18-item 
questionnaire includes four subscales: assertive control, hostility, friendliness and support seeking. Patient questionnaires were adapted by exchanging "I" to "staff". An example question would be "I handle rules in a strict manner".

Perceptions of Fair Interpersonal Treatment Scale (Donovan, Drasgow \& Munson, 1998): This 18-item questionnaire was developed from the literature surrounding organisational justice. It was originally used to examine employee's perceptions of fair treatment from their supervisors and colleagues, but was adapted for the current research. An example question would be "Staff members yell at patients".

The Engagement in Meaningful Activities Survey (EMAS; Goldberg, Britnell \& Goldberg, 2002) was completed by patients only. This 12-item questionnaire examines the extent to which patients find meaningfulness in their day-to-day activities. An example question would include "The activities I do help me take care of myself".

Direct and Indirect Patient Behaviour Checklist - Hospital version revised (DIPC-HR; Ireland \& Rowley, 2007). This was used for patients only, comprising of a behavioural checklist that includes two sections; self-reported intra-group aggression (i.e. aggression behaviours within groups) and self-reported victimisation (i.e. being a victim of aggression). Participants are asked to indicate which behaviours they have engaged in and which behaviours have happened to them within the past month. An example question would be "I have deliberately pushed another patient”.

Ward incident data. Data collection sheets designed by the lead researcher were used to collect ward incident data. This included data about the number of patients on the ward and its dependency level, as well as date, time, location, and type of incident. The number of patients involved in off-ward activities was also recorded. This noted the number of patients 
on each ward and the consequent numbers who engaged in off-ward activities, and the mean overall number of activities engaged in off-ward per ward.

\subsection{Procedure}

Ethical approval for this study was obtained from the Health Research Authority and the University of Central Lancashire, UK. Data was collected from 13 wards at a high secure hospital. The same procedure for approaching staff and patients, as in the earlier study, was utilised. Incident data was extracted from the clinical information database and collected using the sheet designed by the lead researcher.

9. Results

For participant questionnaires, missing data was not above $0.5 \%$ for any variables. Expectation Maximisation was used to estimate missing data. No multivariate outliers were found. Only univariate outliers were changed to make them less extreme.

\section{$9.1 \quad$ Factor analysis}

The EMAS or IMI-C scale are widely used and have been found to have a robust factor structure (Eakman, 2011, Eakman, 2014, Eakman, 2015, Eakman, Carlson \& Clark, 2010, Kiesler \& Schmidt, 2006). Therefore, factor analysis was not performed for these.

Principal components analysis was used to extract factors from the SCIBI (KaiserMeyer-Olkin Measure of Sampling Adequacy = 0.82; Bartlett's Test of Sphericity, $\mathrm{p}<0.001$ ). The four factor structure suggested by Willems et al. (2010) was not supported. Four factors were extracted. One factor had a low reliability $(\alpha=.53)$ which could only be improved slightly 
by the removal of one item. As this scale consisted of only three factors to begin with and the increase in reliability was slight, the whole scale was removed from further analysis. This left three factors.

The first factor was named Openness $(\alpha=.87)$. This was in agreement with the 'Friendliness' subscale proposed by Willems et al. (2010). However, it was termed openness in order to differentiate this scale from the 'Friendly' subscale on the IMI-C. It measured the extent to which staff liked to interact with patients and how much they valued patients. Two items were removed from this scale due to low item-total correlations and a lower alpha score.

The second factor extracted was named Hostile Control $(\alpha=.85)$. It included items addressing staff anger and inability to be flexible. These items were mapped onto hostility and control subscales by Willems et al. (2010). One question was removed from this scale to improve reliability.

The final factor extracted from the SCIBI was named Assertive Control $(\alpha=.67)$. It included items relating to the strictness of staff rules. All of these items were included in the original assertive control subscale proposed by Willems et al. (2010), and so the name was kept the same. The reliability of this scale could have been improved by removing one item. However, the scale only includes three items and the improvement was only slight. So, the item was retained.

Principal components analysis was also used to extract factors from the Perceptions of Fair Interpersonal Treatment scale (Kaiser-Meyer-Olkin Measure of Sampling Adequacy = 0.94; Bartlett's Test of Sphericity, $\mathrm{p}<0.001$ ). Three factors were originally extracted. However, one of these factors only consisted of one item so it was removed from further analysis. The first factor was named Fair Treatment $(\alpha=.95)$. Items detailed treating patients with respect, appreciation of their hard work and the dealing of complaints in a fair manner. 
The second factor had items relating to staff swearing and shouting at patients. This factor was named Staff Professionalism $(\alpha=.71)$.

\subsection{Incidents, self-reported aggression and physical environment}

Data from 1,941 incidents (staff recorded) were collected, including aggressive and non-aggressive incidents. These were correlated with physical environment factors, and are presented in Table 2.

<Insert Table 2 here>

\subsection{Physical factors and off-ward activity}

Strong negative correlations were found between the number of patients involved in off-ward activities and the number of incidents; this indicated that there were fewer incidents on wards where more patients were involved in off-ward activities.

\subsection{Perceptions of interpersonal style}

A MANOVA was conducted to investigate whether patients and staff had significantly different views about interpersonal style. Pillai's trace showed that there was a significant difference between the two groups $(\mathrm{V}=0.92, \mathrm{~F}(8,204)=277.77, \mathrm{p}<0.001)$. Patients perceived staff members to have a more dominant $(\mathrm{F}(1,211)=141.24, \mathrm{p}<0.001)$, hostile $(\mathrm{F}(1,211)=$ 172.40, $\mathrm{p}<0.001)$, hostile control $(\mathrm{F}(1,211)=504.52, \mathrm{p}<0.001)$ and submissive interpersonal style $(\mathrm{F}(1,11)=166.01, \mathrm{p}<0.001)$ than staff perceptions. Staff, however, believed their interpersonal style to be more friendly $(F(1,211)=329.57, \mathrm{p}<0.001)$, open $(\mathrm{F}(1,211)=96.37$, $\mathrm{p}<0.001)$, more characterised by affiliation $(\mathrm{F}(1,211)=328.94, \mathrm{p}<0.001)$ and with higher 
levels of assertive control $(\mathrm{F}(1,211)=150.77, \mathrm{p}<0.001)$ than patients. A one-way ANOVA also revealed that staff perceived patients to be treated more fairly than patients did $(\mathrm{F}(1,61)$ $=40.89, \mathrm{p}<0.001)$. Staff perceived themselves to have a higher level of professionalism than patients did $(\mathrm{F}(1,62)=62.22, \mathrm{p}<0.001)$.

\subsection{The mediating effect of fairness between staff interpersonal style, incidents and intra-} group aggression

In order to investigate the relationship between staff interpersonal style, fairness and incidents further, mediation analysis was undertaken. The results are shown in Figures 3 to 5 .

\section{$<$ Insert Figures 3 to 5 here>}

This demonstrated that the perception of fair treatment mediated a number of relationships between staff interpersonal style and incidents. Patient perception of fair treatment mediated the effect of patient perception of hostile interpersonal style and patient perception of affiliation on self-reported intra-group aggression (Figure 3). Overall, perception of fair treatment was found to mediate the effect of patient perception of dominant interpersonal style, hostile interpersonal style and assertive control on self-reported victimisation incidents (Figure 4).

Patient perception of fair treatment was also found to mediate the link between interpersonal style and staff reported aggressive incidents. There was a significant indirect effect of perception of hostile interpersonal style on aggressive incidents via patient perception of fair treatment $(b=93.36, z=2.06, p=0.04)$. This effect suggests that an interpersonal style characterised by hostility is linked to greater numbers of staff-reported aggressive incidents via the reduction of perception of fairness (Figure 5). 
9.6 The mediating effect of number of patients involved in off-ward activities between staff interpersonal style and staff reported incidents

Mediation analysis showed a significant indirect effect of off-ward activities on aggressive incidents, mediated through staff perception of their own hostile control $(b=-18.41$, $\mathrm{z}=-3.65, \mathrm{p}<0.001)$ and staff perception of assertive control $(\mathrm{b}=-9.25, \mathrm{z}=-2.16, \mathrm{p}=0.03)$. This effect indicated that lower levels of off-ward activity was related to reductions in staff perceptions of both hostile and assertive control, which in turn were related to fewer aggressive (staff reported) incidents. Similarly, a significant indirect effect of the (increased) number of patients involved in activities on non-aggressive incidents through staff perception of hostile control $(b=-9.23, z=-3.32, p<0.001)$ and staff perception of assertive control $(b=-5.54, z$ $=-2.53, p=0.01)$ was found. This effect indicated that the number of patients involved in offward activities is related to reductions in staff perceptions of hostile and assertive control, which in turn are related to fewer numbers of non-aggressive incidents (see Figure 6).

$<<$ Insert Figure 6>>

10. General discussion

Crowding, lack of (meaningful) activities and negative interpersonal reactions were identified in the initial study as important considerations in trying to predict incidents (e.g. Chaplin et al, 2006; Hallet et al, 2014; Meehan et al, 2006; Pulsford et al, 2013; Rocheleau, 2013, Soares et al, 2000; Virtanen et al, 2011, Wortley, 2002), with a focus more on environmental factors than the interaction between those residing/working within secure 
settings. Thus, the literature examined as part of Study 1 placed a greater emphasis on the environment. This was consistent more with the expectations of Deprivation Theory, and to some extent, General Strain Theory; although there was no evidence linking environment and impacts directly. Study 2 supported the importance of specific aspects of the social environment in the prediction of incidents, particularly in relation to the cohesive nature of the patient group and the extent to which the environment fulfils needs (i.e. therapeutic hold and involvement in the service), but noted the type of incident to be important and discounted a number of social environmental predictors. Study 3 explored a wider range of social and environmental variables and demonstrated fewer incidents on wards where patients were more involved in off-ward activities. This link was mediated by specific social-interpersonal variables. Specifically, raised incident levels were associated with a controlling and hostile staff interpersonal style, while reduced numbers of incidents were associated with staff interpersonal styles that were characterised by affiliation and openness.

Patients perceived staff interpersonal style to be more negative than the staff's own perceptions of their interpersonal style. Perceptions as a key variable was outlined further by the importance of perceived fairness, with this mediating the relationship between interpersonal style and incidents; notably when patients perceived lower levels of fairness. The importance of interpersonal style and meaningful activity was consistent with what had emerged from the initial literature review (Study 1), with the final study presenting support for this, yet noting that there was more to the association with interpersonal style and incidents than that captured in the pre-existing literature.

Consistent with the prediction, the current research demonstrated that negative aspects of the environment, namely poorer patient cohesion, the environment not fulfilling therapeutic needs or involving patients in off-ward activities, were associated with increases in security 
incidents. This is consistent both with Deprivation and Strain Theory, lending support to the damaging aspects of secure environments in terms of promoting indiscipline. It was the number of patients on a ward that were involved in off-ward activities that related to (fewer) aggressive and non-aggressive incidents. This provided partial support for the arguments of the General Strain Theory (Agnew, 2009) and the Good Lives Model (Ward \&Gannon, 2006), namely that engagement in activity is needed to prevent incidents. Although the overall number of activities a patient engaged in, and the meaningfulness of these activities did not appear to have an influence, it could be argued that the more patients were involved in activities the more relaxed, distracted and less crowded a ward is, thus leading to reduced strain.

The environmental factors of importance were limited in nature, with a number of potential variables discounted. It appears more fitting to conclude that the prediction concerning the importance of environmental variables to security incidents was only partially supported in this regard and that core variables appeared to be leaning towards the specifics of interpersonal relationships, including feeling involved and valued. The focus on activities having value, feeling involved in the service and patient cohesion to offset incidents, suggests particular value in the application of the Good Lives Model, which would argue that needs (primary goods) are a driver for behaviour. In this sense the agency, community and knowledge components of the Good Lives Model become valuable considerations. This is, of course, speculative and a primary emerging factor overall was interpersonal interactions and the perceptions of these.

Perceptions of interpersonal style were notably of greater value than other factors, and data supported the prediction that staff's negative interpersonal styles, namely those characterised by hostility and dominance, predicted increased numbers of security incidents. The related prediction that perceived unfairness being related to increased levels of security 
incidents was also supported and proved to be an important mediator between interpersonal style and security incidents; essentially, the more unfair staff were perceived to be, the more incidents occurred.

The relationship between patients and staff is thus clearly important. Within this, a lack of quality support from others and perceived staff failure to value patients and show respect were key. There was a suggestion that improved communication, as a result of better relationships, would allow issues to be dealt with more effectively. Some support for the core components of General Strain Theory (Agnew, 2001) were therefore demonstrated in that effective communication could be thought to reduce the strain associated with negative relationships. In addition, the finding that staff failure to value patients and show respect (i.e. perceived unfairness), was associated with incidents supports the theory that procedural justice and legitimacy of authority can influence behaviour. Showing patients respect is one of the main issues thought important in communicating fairness (Jackson et al, 2010). Due to the link between greater fairness and greater perceptions of legitimacy of authority (Brunton-Smith \& McCarthy, 2016; Jackson et al, 2010; Tyler \& Fagan, 2008), this study provides support for the argument that procedural justice is also likely to be influencing security incidents.

The findings regarding a lack of engagement in meaningful activities was also of interest and could also be linked to the concept of fairness. The systematic review suggested that activities had to be consistent and meaningful in order to protect against incidents. If patients do not feel that staff are concerned with their well-being, they are likely to feel that they are being treated unfairly (Jackson et al, 2010). It can be argued that by not providing activities for the patients to engage in, or not providing activities a patient deems as meaningful, may be attributed to a lack of concern about well-being. Therefore, a patient may believe themselves to have been treated unfairly, which in turn would reduce perceptions of legitimacy and 
increase in the frequency of security incidents. This finding also supports the contribution of the Good Lives Model (Ward \& Gannon, 2006). A lack of activities may make it difficult to meet patient needs of play, excellence, relatedness and creativity. In turn, patients engage in incidents as a means of having these needs met.

One of the main issues described by Jackson et al. (2010) as being important in the perception of fairness is the issue of 'voice'. This reflects the need to provide opportunities to participate in decision-making. A lack of patient involvement, as found in this study, may reflect a lack of voice. In turn, this would reduce patient perception of fairness and reduce their perception of legitimacy of authority. This would then increase the likelihood that they would engage in security incidents (Tyler, 2006).

Collectively, these findings suggest General Strain Theory and Deprivation theory need to be extended to capture staff interpersonal functioning and perceptions of this by patients as a unique environmental or cultural factor. A role for Importation Theory is also indicated. Here, for example, it could be speculated that it is the pre-existing characteristics of patients, such as attribution biases, that are promoting misperceptions of staff style or, and perhaps equally, it could be that staff interpersonal style is problematic. The latter would suggest that it may be the characteristics that staff import with them into the environment that are therefore important. This would extend the concept of Importation Theory beyond a mere focus on residents in secure setting to other important groups also present, namely staff. Equally, it could be the hospital's cultural environment that moulds the styles of staff and promotes a hostile perception in patients. This fits with the concept of complimentary (Lillie, 2007), suggesting that the interpersonal style of staff may be directly associated with the way patients choose to behave. This was further supported by the finding that the fairness patients perceived in relation to staff behaviour (or rather a lack of fairness) was also related to incidents, and 
mediated the relationship between interpersonal style and aggressive incidents. It supports the notion that perceptions of fairness can directly influence patient behaviour (Jackson et al, 2010; Tyler, 2006), with the perception of fairness considered here as an interpersonal variable.

Whatever explanation is preferred, theories such as Direct Importation, General Strain Theory and Deprivation Theory may be insufficient in isolation to explain how security incidents are being promoted in secure settings. Instead, a more integrated approach to understanding security incidents is emerging, one that accounts for interpersonal interactions between residents and staff. Such an approach should, arguably, account more for the perceptions held by both patients and staff since these appear to represent the core variables of interest and also those malleable to change. Cognition, including attributions and misattributions, appears to be missing in our understanding of what promotes indiscipline. There is a need to align current thinking more with social-cognitive models of understanding, which emphasise the process of decision-making prior to choices being made (i.e. to engage in a security incident). It would allow for the capturing of biases and attributional errors (e.g. Huesmann, 1998; Ireland, 2018). It could also offer some explanation as to why perceived unfairness becomes so important because this could, if associated with a negative emotion, lead to negative scripts being accessed and enacted. Applying such models would help explain the importation element of biases and attitudes that is arguably being evidenced through reported perceptions, because such models outline the pre-existing and learnt element of such biases/attributions. Current models trying to explain indiscipline in secure settings are failing to account for the important role of social-cognition.

The current findings can be combined to propose a preliminary framework for predicting security incidents, one that accounts for interpersonal factors, perceptions and 
activities. This preliminary framework, the McKenna Framework for understanding Incidents in Secure Settings (M-FISS), is indicated in Figure 7.

$$
<<\text { Insert Figure } 7 \text { here }>>
$$

The M-FISS comprises relationships, staff interpersonal style, patient perception of injustice and activities as its four core components. It proposes that a lack of good quality relationships increases the likelihood of security incidents. This includes patients and/or staff relationships that are characterised by low levels of support and communication. This is consistent with Deprivation Theory (Irwin \& Cressey, 1962) and General Strain Theory (Agnew, 2009), which both argue that a lack of intimate relationships and poor social interactions are strainful experiences. It is also consistent with the Good Lives Model (Ward \& Gannon, 2006), which would argue for a drive to seek relatedness and community. This need to achieve this and the 'strain' of not doing so could arguably lead to patients using maladaptive means to achieve needs, such as displaying aggression to gain attention from staff to meet the need for relatedness (regardless of the quality of this attention). The route by which this operates, however, is not yet identified.

According to General Strain Theory experiences of strain can increase the numbers of incidents due to an increase in levels of stress, anger and frustration (Agnew, 2001). Although these were not assessed directly in the current research, they are proposed as a means through which incidents were occurring, also allowing for a more social-cognitive explanation to be integrated into a proposed framework. Here, emotions represent an untested element of the framework that is worthy of future consideration. 
The interpersonal style of staff presents an additional core consideration in the M-FISS, and fits with the notion of complementarity (Lillie, 2007) where there is thought to be a mirroring of (hostile/dominant) styles from staff to patients, leading to incidents. Again, the route by which negative staff interpersonal style is likely to contribute to an incident is not yet captured but the framework suggests that this could, again, be via negative emotions, particularly when there is complementarity leading to an escalation of the expressed emotions (e.g. hostility on both sides). A further missing element for consideration represents how this staff interpersonal style developed. It could be suggested it was a pre-existing imported characteristic and/or developed or facilitated by the specifics of working in a secure setting. This is an area for future consideration but the M-FISS is clear in considering the interpersonal style of staff as a key component to the promotion or otherwise of security incidents. It also suggests some complementarity taking place between the environment, and its arguably hostile and straining elements, and interpersonal styles.

Further complimenting the M-FISS is the inclusion of patient perceptions, specifically injustice. Perceptions of fairness presented as a core variable. Consequently, it appears as a potential route through which other aspects of the framework, such as relationships, can be understood. It also relates back to the staff interpersonal style, resulting in patients believing they are being treated unfairly, leading to a higher likelihood of indiscipline. Since this highlights a role for perception, the M-FISS offers a potential for attributional or expectancy beliefs as likely important to account for. This is again in support of the social-cognition understandings noted earlier (e.g. Huesmann, 1998).

Finally, the M-FISS incorporates the number of patients involved in off-ward activities, arguing that the fewer patients are involved in activities, the more controlling staff interpersonal style is likely to be perceived which, in turn, increases the likelihood of incidents. 
This is supported by Deprivation theory (Irwin \& Cressey, 1962) and the Good Lives Model (Ward \& Gannon, 2006), with a lack of daily activities argued here to represent a further source of strain, again potentially through negative emotions but also accounting for the pivotal role of staff interpersonal style.

There are limitations to this research. For example, the research attempted to link ward perceptions of meaningfulness to the number of ward incidents, and where it may have been more useful to measure this on an individual level. Individual perceptions of meaningfulness could be assessed and then linked to individual involvement in incidents. This would be important when differences in perceptions of meaningfulness are considered. It was also noted that the ratings for meaningfulness did differ quite significantly and using this scale at ward level may not fully assess this variable's contribution to incidents. Further, ward dependency level was not controlled for, meaning that some results may instead be linked to dependency level. For example, lower dependency wards generally had more patients involved in off-ward activities. Therefore, it may be that the effect of this variable on incidents can actually be attributed to lower ward dependency. Future research should look at this in order to investigate the relationship more clearly.

\section{Conclusion}

In conclusion, the studies in this paper have allowed for a clearer understanding of the factors involved in the prediction of security incidents in high secure psychiatric care. It is only by each study building on the previous that there has been an opportunity to understand some of these components of prediction, and where factors previously considered to be integral have not had the same importance applied to them, such as environmental factors. Indeed, what this 
research has noted is the importance of relational security in predicting security incidents, such as patient perception of fairness and perceived injustice, interpersonal styles between staff and patients, along with patient engagement in off-ward activities. 
Figure 1. Papers included and excluded at each stage of the search process.

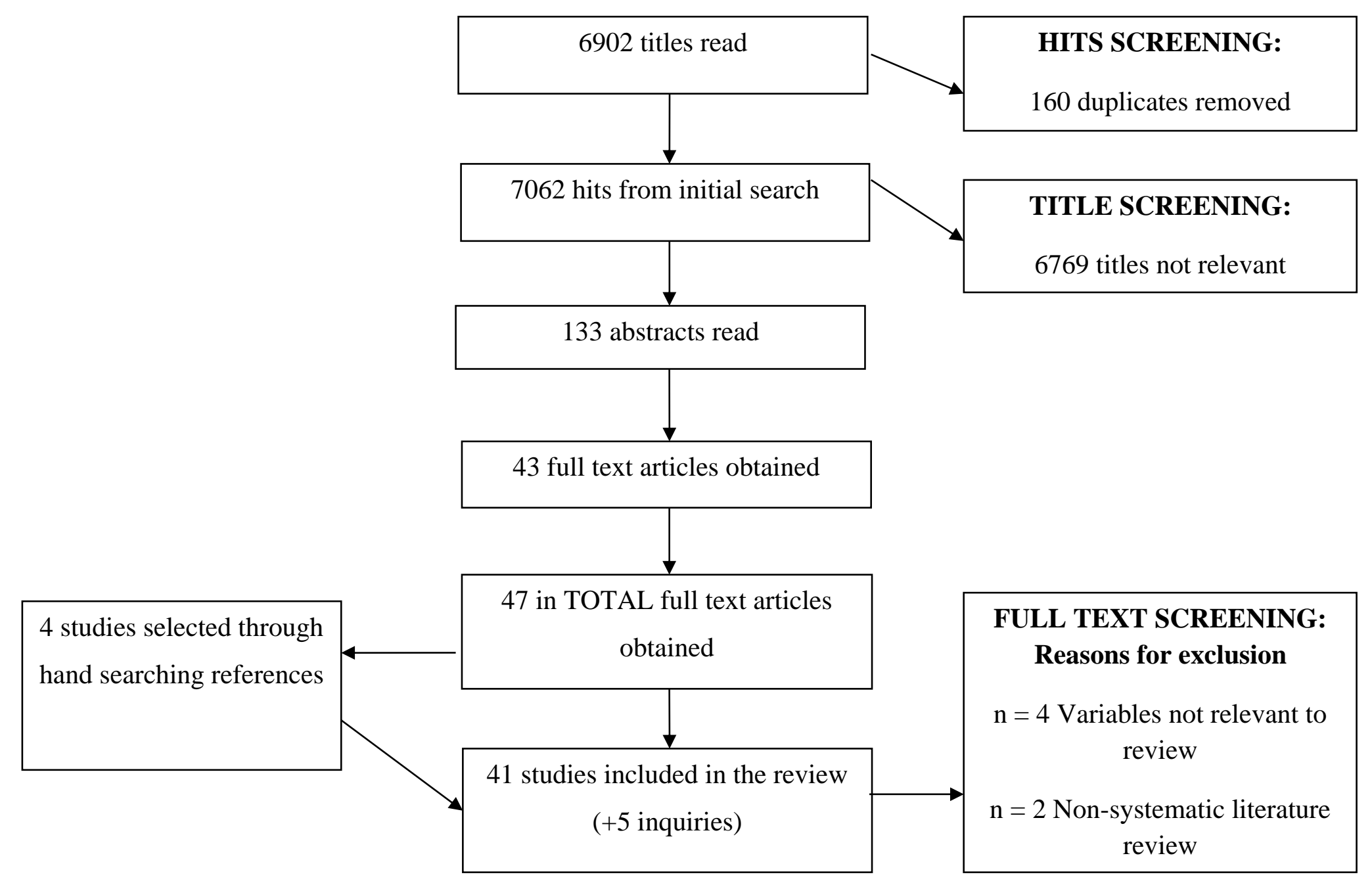


Figure 2. Fair treatment as a mediating link between hostile interpersonal style, affiliation and intra-group aggression

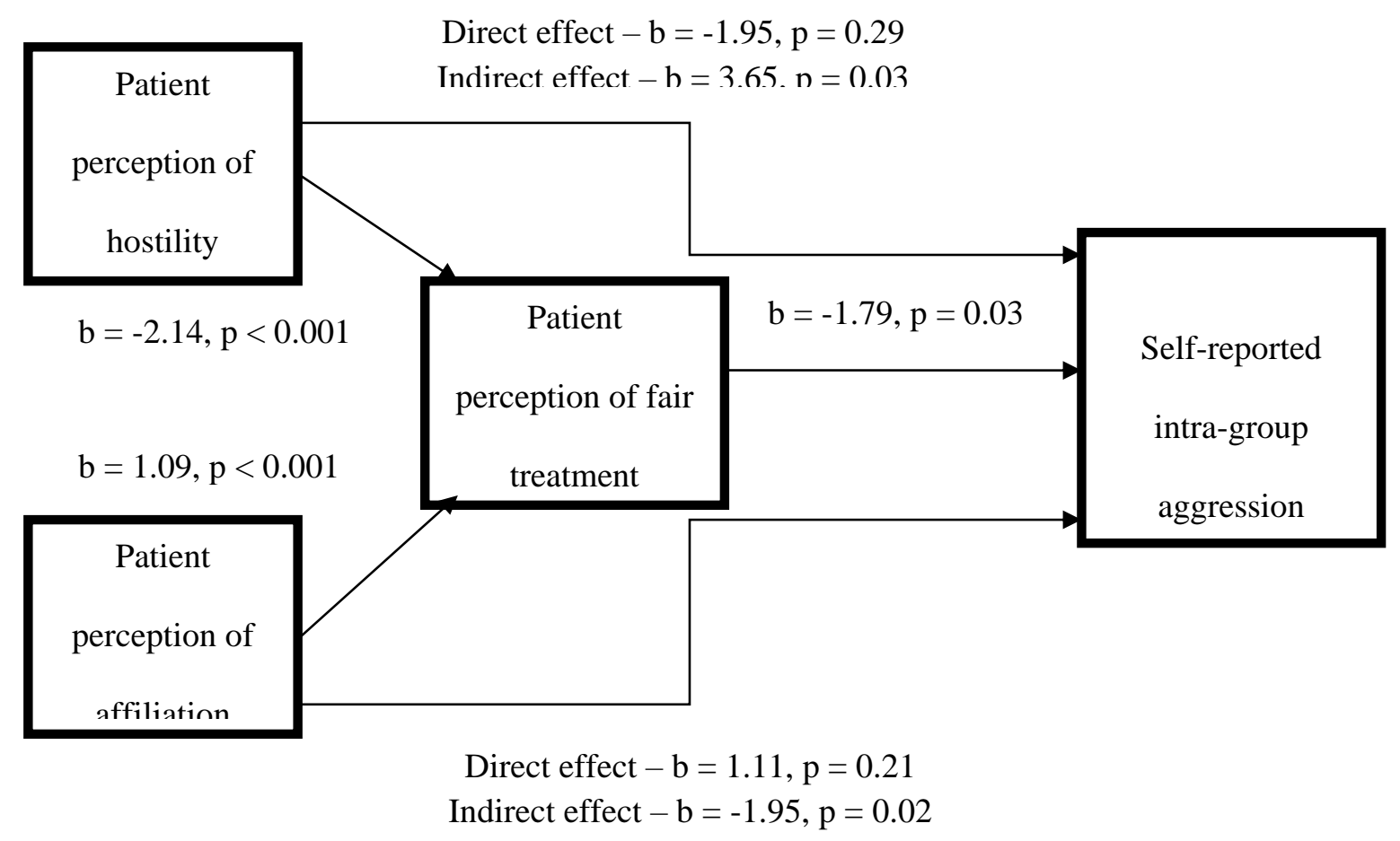




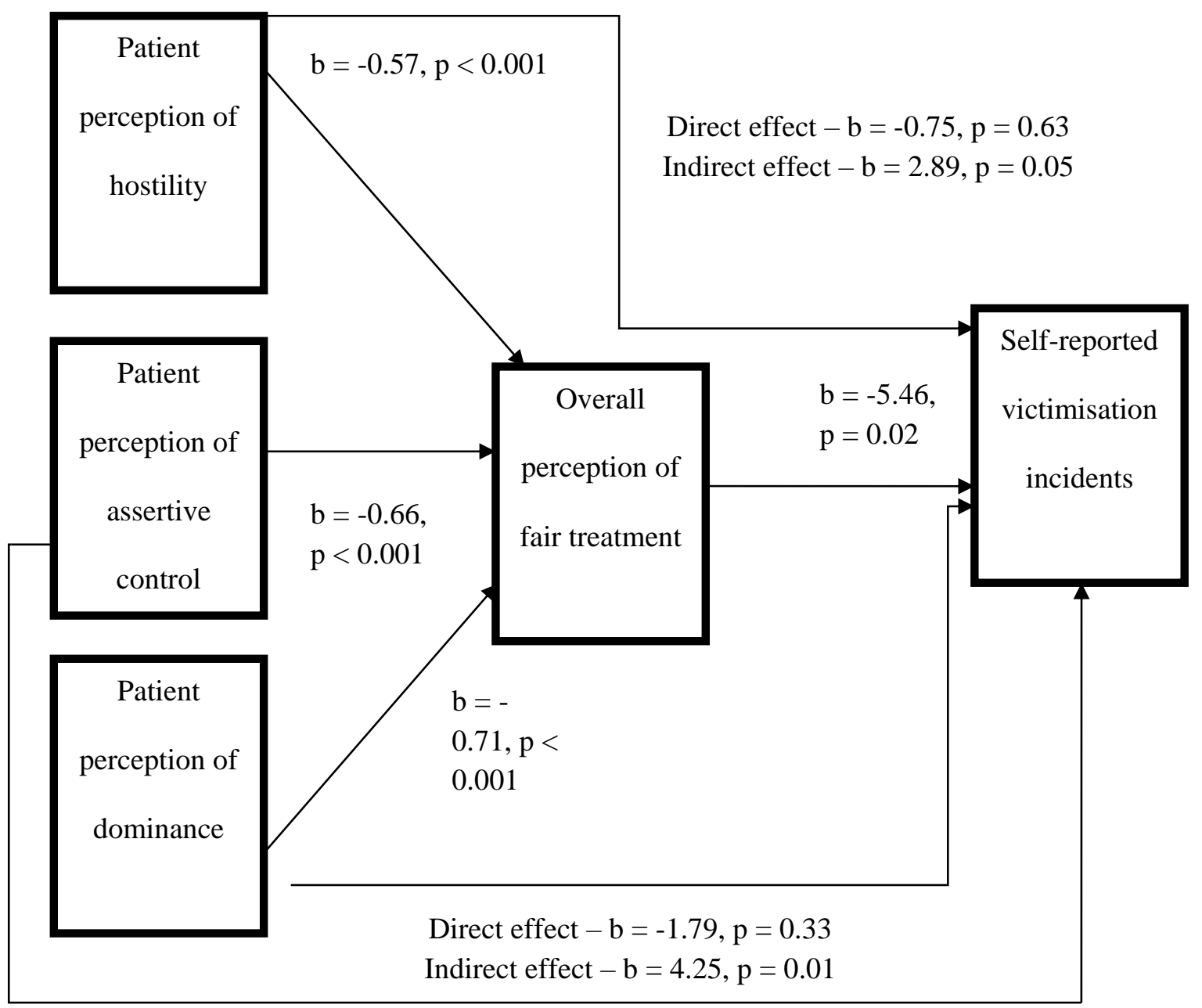

Direct effect $-b=-1.32, p=0.41$

Indirect effect $-b=3.61, p=0.01$

Figure 3. Fair treatment as a mediating link between dominant interpersonal style, hostile interpersonal style, assertive control and victimisation incidents 


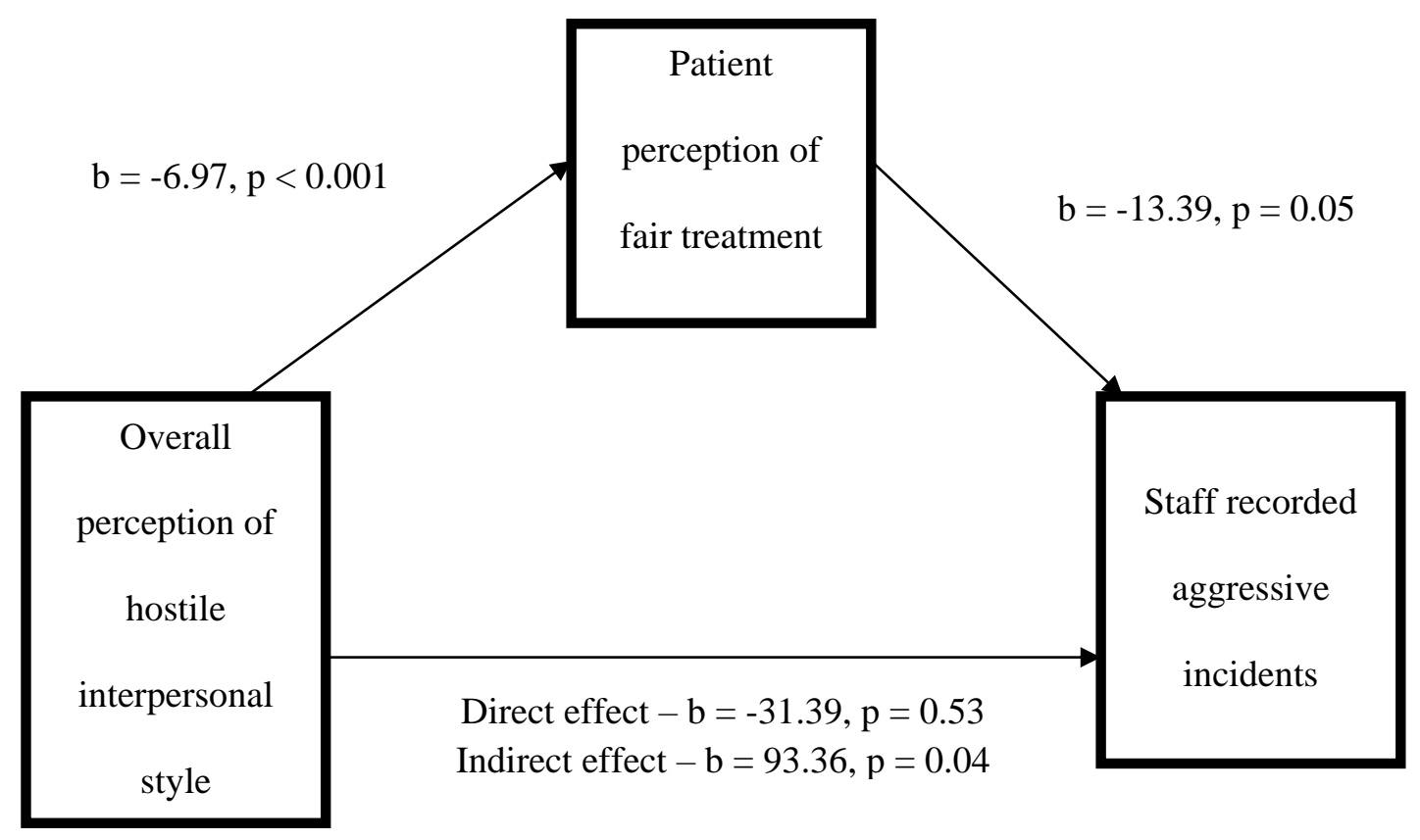

Figure 4. Fair treatment as a mediating link between hostile interpersonal style and aggressive incidents 


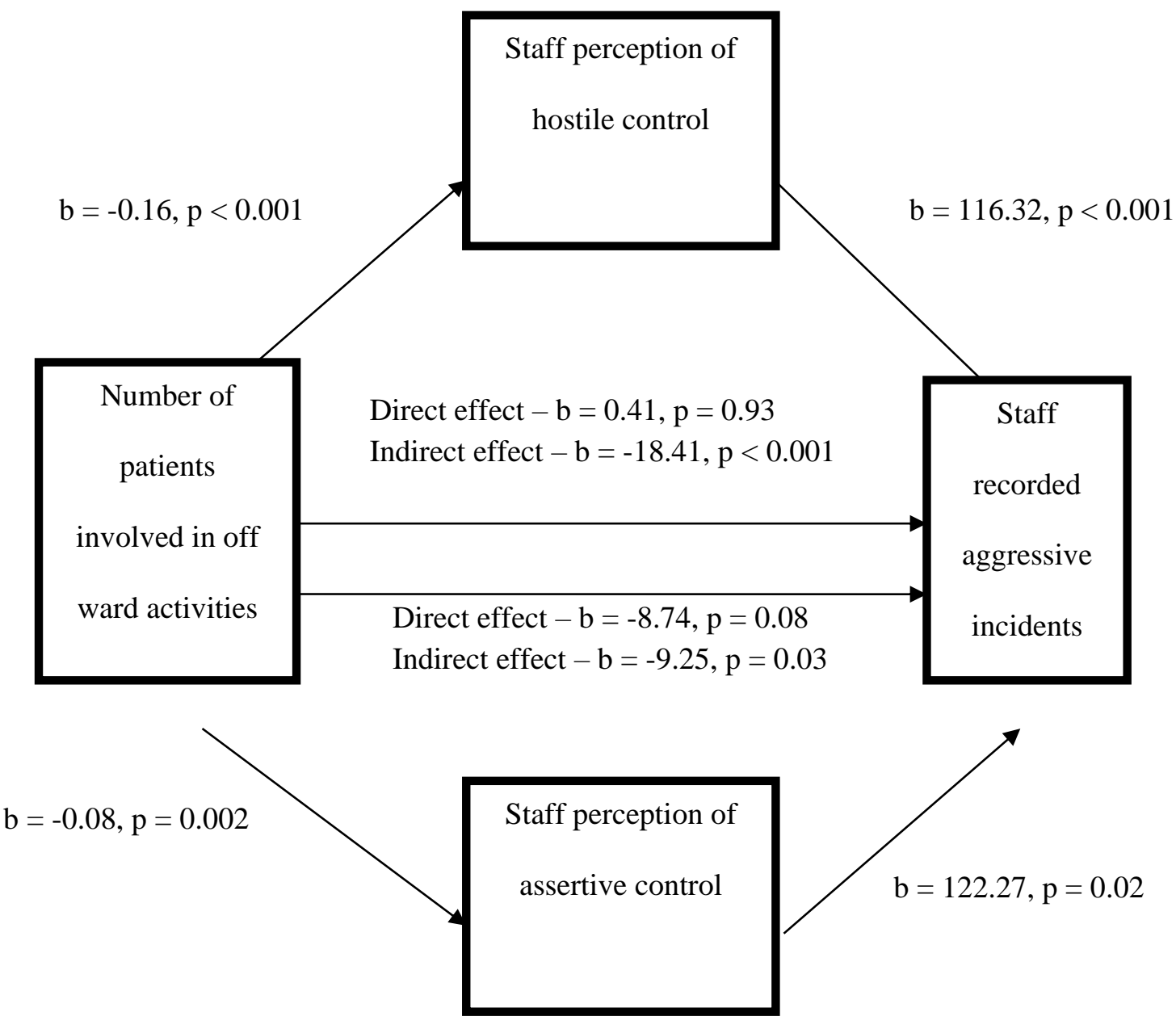

Figure 5. Staff perception of hostile control and assertive control as mediating links between the number of patients involved in activities and aggressive incidents 


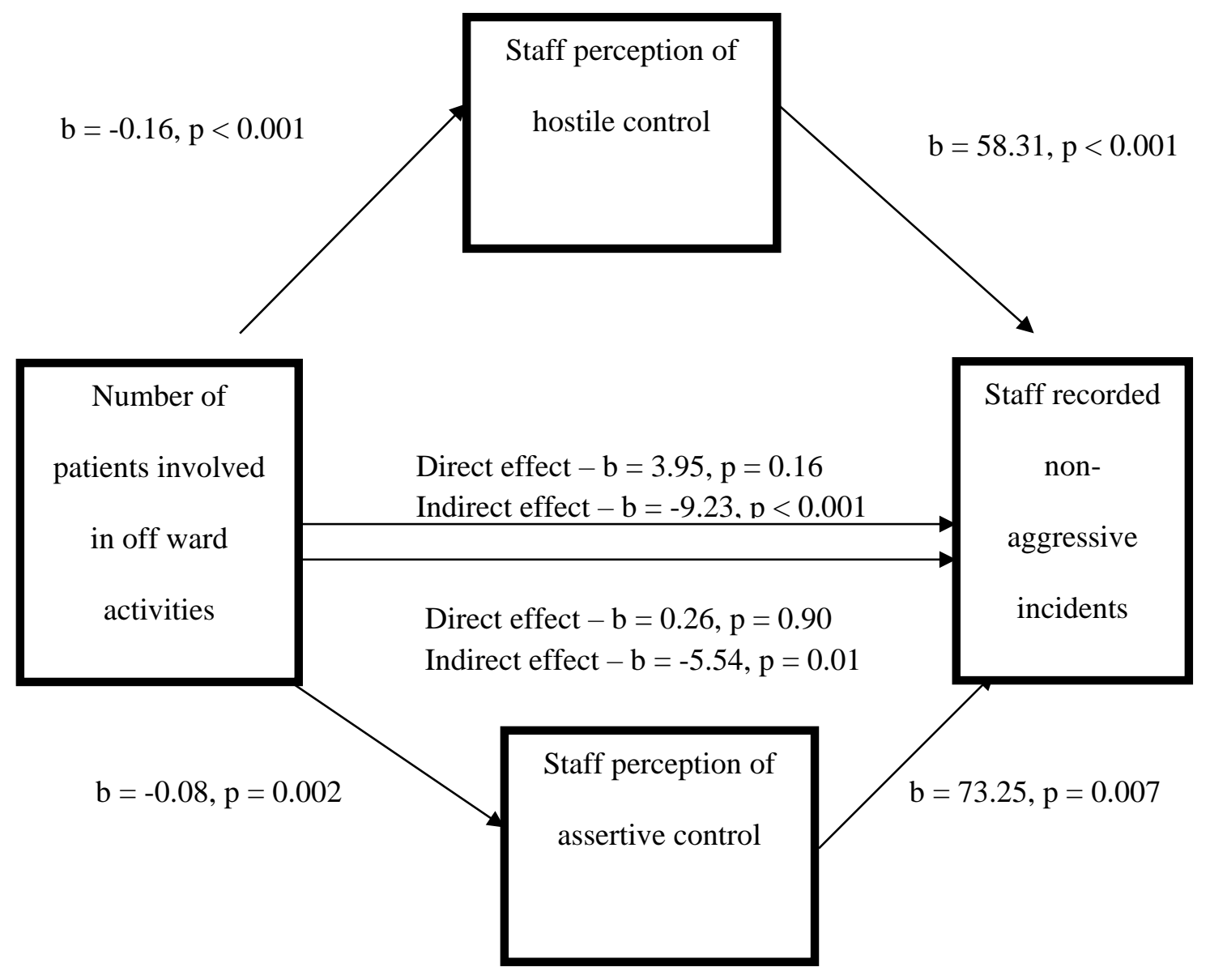

Figure 6. Staff perception of hostile control and assertive control as mediating links between the number of patients involved in activities and non-aggressive incidents 
Figure 7. McKenna Framework for understanding Incidents in Secure Settings (M-FISS)

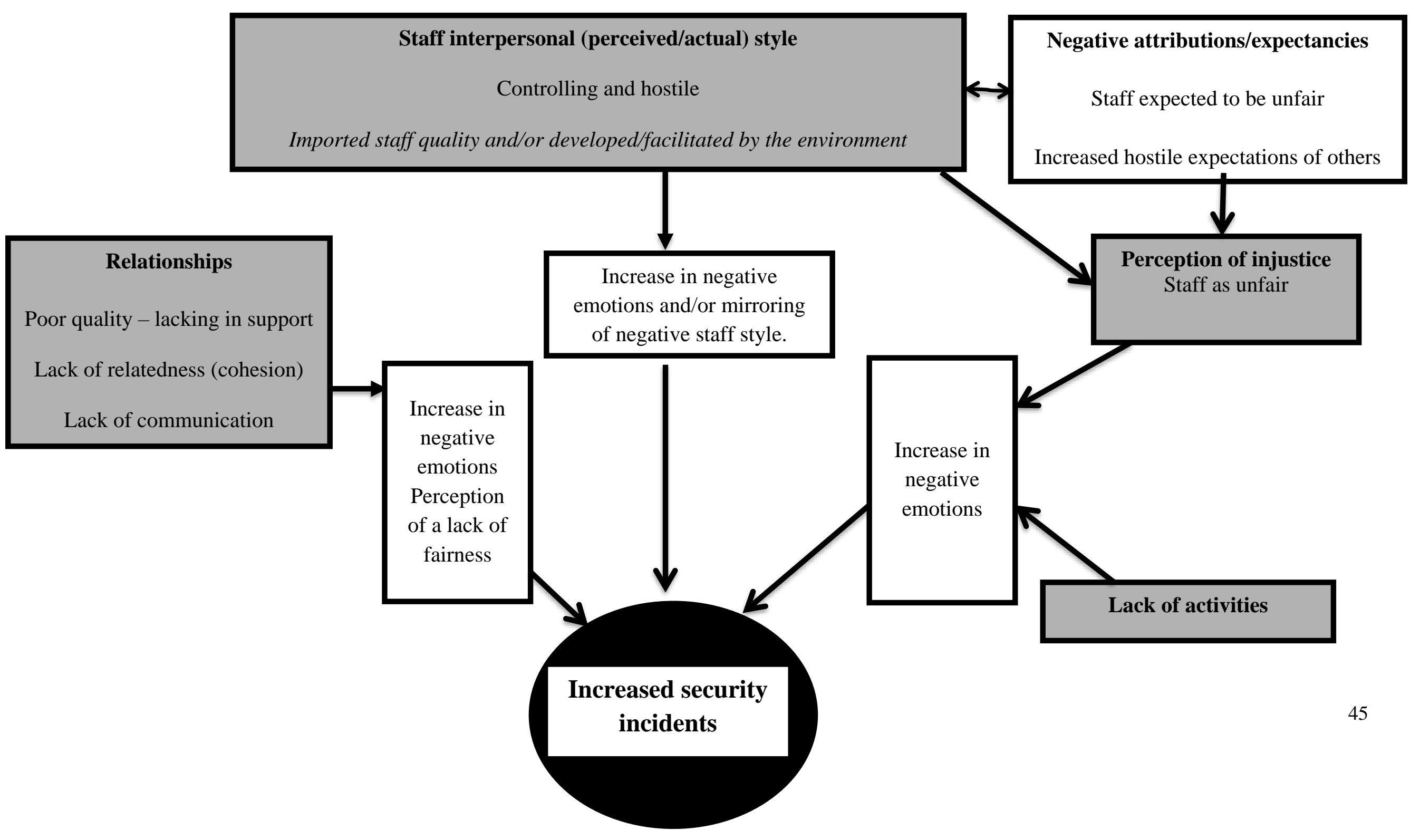


Table 1. Mean scores (and standard deviations) for relational security, service involvement, patient cohesion, and therapeutic hold scales.

\begin{tabular}{|c|c|c|c|c|c|c|c|c|c|c|c|c|c|c|}
\hline & $\begin{array}{l}\text { Ward } 1 \\
\text { (S.D) }\end{array}$ & $\begin{array}{l}\text { Ward } 2 \\
\text { (S.D) }\end{array}$ & $\begin{array}{l}\text { Ward } 3 \\
\text { (S.D) }\end{array}$ & $\begin{array}{l}\text { Ward } 4 \\
\text { (S.D) }\end{array}$ & $\begin{array}{l}\text { Ward } 5 \\
\text { (S.D) }\end{array}$ & $\begin{array}{l}\text { Ward } 6 \\
\text { (S.D) }\end{array}$ & $\begin{array}{l}\text { Ward } 7 \\
\text { (S.D) }\end{array}$ & $\begin{array}{l}\text { Ward } 8 \\
\text { (S.D) }\end{array}$ & $\begin{array}{l}\text { Ward } 9 \\
\text { (S.D) }\end{array}$ & $\begin{array}{l}\text { Ward } \\
10 \\
\text { (S.D) }\end{array}$ & $\begin{array}{l}\text { Ward } \\
11 \\
\text { (S.D) }\end{array}$ & $\begin{array}{l}\text { Ward } \\
12 \\
\text { (S.D) }\end{array}$ & $\begin{array}{l}\text { Ward } \\
13 \\
\text { (S.D) }\end{array}$ & $\begin{array}{l}\text { Total } \\
\text { (S.D) }\end{array}$ \\
\hline $\begin{array}{l}\text { Number of } \\
\text { patients }\end{array}$ & 14 & 15 & 20 & 18 & 19 & 19 & 13 & 11 & 12 & 17 & 15 & 13 & 9 & 195 \\
\hline $\begin{array}{l}\text { Relational } \\
\text { security }\end{array}$ & $\begin{array}{l}13.71 \\
(1.90)\end{array}$ & $\begin{array}{l}14.26 \\
(3.21)\end{array}$ & $\begin{array}{l}14.32 \\
(4.36)\end{array}$ & $\begin{array}{l}13.88 \\
(3.93)\end{array}$ & $\begin{array}{l}13.32 \\
(2.11)\end{array}$ & $\begin{array}{l}13.32 \\
(1.67)\end{array}$ & $\begin{array}{l}14.67 \\
(1.97)\end{array}$ & $\begin{array}{l}11.67 \\
(3.50)\end{array}$ & $\begin{array}{l}14.17 \\
(2.07)\end{array}$ & $\begin{array}{l}14.07 \\
(3.77)\end{array}$ & $\begin{array}{l}15.37 \\
(3.92)\end{array}$ & $\begin{array}{l}14.96 \\
(2.49)\end{array}$ & $\begin{array}{l}14.78 \\
(3.99)\end{array}$ & $\begin{array}{l}14.16 \\
(3.07)\end{array}$ \\
\hline $\begin{array}{l}\text { Service } \\
\text { involvement }\end{array}$ & $\begin{array}{l}10.71 \\
(1.95)\end{array}$ & $\begin{array}{l}11.84 \\
(2.95)\end{array}$ & $\begin{array}{l}12.18 \\
(3.19)\end{array}$ & $\begin{array}{l}10.18 \\
(2.17)\end{array}$ & $\begin{array}{l}10.58 \\
(1.87)\end{array}$ & $\begin{array}{l}10.68 \\
(1.49)\end{array}$ & $\begin{array}{l}11.19 \\
(1.75)\end{array}$ & $\begin{array}{l}10.50 \\
(2.35)\end{array}$ & $\begin{array}{l}10.61 \\
(2.03)\end{array}$ & $\begin{array}{l}12.06 \\
(3.51)\end{array}$ & $\begin{array}{l}11.94 \\
(3.36)\end{array}$ & $\begin{array}{l}9.33 \\
(2.25)\end{array}$ & $\begin{array}{l}12.00 \\
(3.50)\end{array}$ & $\begin{array}{l}11.01 \\
(2.65)\end{array}$ \\
\hline $\begin{array}{l}\text { Patient } \\
\text { cohesion }\end{array}$ & $\begin{array}{l}13.62 \\
(2.18)\end{array}$ & $\begin{array}{l}12.69 \\
(2.72)\end{array}$ & $\begin{array}{l}14.36 \\
(2.75)\end{array}$ & $\begin{array}{l}14.97 \\
(2.28)\end{array}$ & $\begin{array}{l}14.21 \\
(1.13)\end{array}$ & $\begin{array}{l}14.79 \\
(1.72)\end{array}$ & $\begin{array}{l}14.50 \\
(2.24)\end{array}$ & $\begin{array}{l}14.33 \\
(1.75)\end{array}$ & $\begin{array}{l}14.59 \\
(2.06)\end{array}$ & $\begin{array}{l}12.87 \\
(2.67)\end{array}$ & $\begin{array}{l}12.95 \\
(2.99)\end{array}$ & $\begin{array}{l}14.93 \\
(2.51)\end{array}$ & $\begin{array}{l}12.22 \\
(2.82)\end{array}$ & $\begin{array}{l}13.96 \\
(2.47)\end{array}$ \\
\hline $\begin{array}{l}\text { Therapeutic } \\
\text { hold }\end{array}$ & $\begin{array}{l}21.52 \\
(1.47)\end{array}$ & $\begin{array}{l}20.30 \\
(2.22)\end{array}$ & $\begin{array}{l}19.87 \\
(2.38)\end{array}$ & $\begin{array}{l}21.69 \\
(1.20)\end{array}$ & $\begin{array}{l}20.68 \\
(1.45)\end{array}$ & $\begin{array}{l}21.05 \\
(1.65)\end{array}$ & $\begin{array}{l}20.38 \\
(1.30)\end{array}$ & $\begin{array}{l}22.17 \\
(2.93)\end{array}$ & $\begin{array}{l}20.00 \\
(1.88)\end{array}$ & $\begin{array}{l}20.20 \\
(3.21)\end{array}$ & $\begin{array}{l}19.21 \\
(2.07)\end{array}$ & $\begin{array}{l}15.52 \\
(1.99)\end{array}$ & $\begin{array}{l}19.11 \\
(3.59)\end{array}$ & $\begin{array}{l}19.88 \\
(2.70)\end{array}$ \\
\hline
\end{tabular}

There are 6 high dependency wards (Wards 1, 2, 7, 8, 9 and 13), and 7 low dependency wards (Wards 3, 4, 5, 6, 10, 11 and 12) 
Table 2. Correlations between patients involved in off-ward activities and the number of security incidents.

\begin{tabular}{|c|c|c|c|c|c|}
\hline & $\begin{array}{l}\text { Patients involved in off-ward } \\
\text { activities }\end{array}$ & $\begin{array}{l}\text { Aggressive } \\
\text { incidents }\end{array}$ & $\begin{array}{l}\text { Non-aggressive } \\
\text { incidents }\end{array}$ & $\begin{array}{l}\text { Self-reported } \\
\text { aggression }\end{array}$ & $\begin{array}{l}\text { Self-reported } \\
\text { victimisation }\end{array}$ \\
\hline Aggressive incidents & $-.83 * *$ & & & & \\
\hline $\begin{array}{l}\text { Non-aggressive } \\
\text { incidents }\end{array}$ & $-.64 *$ & $.79^{* * *}$ & & & \\
\hline $\begin{array}{l}\text { Self-reported } \\
\text { aggression }\end{array}$ & $-.61 *$ & $.67^{*}$ & $.80^{* *}$ & & \\
\hline $\begin{array}{l}\text { Self-reported } \\
\text { victimisation }\end{array}$ & $-.65^{*}$ & $.56^{*}$ & .41 & .31 & \\
\hline
\end{tabular}

$* \mathrm{p}<0.05, * * \mathrm{p}<0.001$ 
References

Agnew, R. (1992). Foundation for a general strain theory of crime and delinquency. Criminology, 30, 47-87

Agnew, R. (2001). Building on the foundation of general strain theory: Specifying the types of strain most likely to lead to crime and delinquency. Journal of Research in Crime and Delinquency, 38, 319-361

Bidna, H. (1975) Effects of increased security on prison violence. Journal of Criminal Justice, 3, 36-46

Blevins, K.R., Listwan, S.J., Cullen, F.T., \& Johson, C.L. (2010) A general strain theory of prison violence and misconduct: An integrated model of inmate behaviour. Journal of Contemporary Criminal Justice, 26 (2), 148-166

Blom-Cooper Sir L., Brown M., Dolan R. and Murphy E. (1992) Report of the Committee of Inquiry into Complaints about Ashworth Hospital, Cmnd 2028, vols 1 and 2. London: HMSO

Bowers, L., Brennan, G., Flood, C., Lipang, M., \& Oladapo, P. (2006). Preliminary outcomes of a trial to reduce conflict and containment on acute psychiatric wards: City Nurses. Journal of Psychiatric and Mental Health Nursing, 13, 165-172

Brunton-Smith, I., \& McCarthy, D.J. (2016). Prison legitimacy and procedural fairness: A multi-level examination of prisoners in England and Wales. Justice Quarterly, 33 (6), 1029-1054

Chaplin, R., McGeorge, M., \& Lelliott, P. (2006) The National Audit of Violence: Inpatient care for adults of working age. Psychiatric Bulletin, 30, 444-446

Collins, M., \& Davies, S. (2005). The Security Needs Assessment Profile: A Multidimensional Approach to Measuring Security Needs. International Journal of Forensic Mental Health, 4, 39-52 
Dack, C., Ross, J., Papadopoulos, C., Stewart, D., Bowers, L. (2013). A review and metaanalysis of the patient factors associate with psychiatric in-patient aggression. Acta Psychiatrica Scandinavica, 127, 255-268

Daffern, M., Day, A., \& Cookson, A. (2012) Implications for the prevention of aggressive behaviour within psychiatric hospitals drawn from interpersonal communication theory. International Journal of Offender Therapy and Comparative Criminology, 56 (3), 401-419

Deci, E.L. \& Ryan, R.M. (2000). The "what" and the "why" of goal pursuits: Human needs and the self-determination of behavior. Psychological Inquiry, 11, 227-268

Department of Health (2010). Your Guide to Relational Security: See, Think, Act. London: Department of Health Secure Services Policy Team.

Donovan, M. A., Drasgow, F., \& Munson, L. J. (1998). The Perceptions of Fair Interpersonal Treatment Scale: development and validation of a measure of interpersonal treatment in the workplace. Journal of Applied Psychology, 83 (5), 683-692

Duxbury, J. (2002). An evaluation of staff and patient views of and strategies employed to manage inpatients aggression and violence on one mental health unit: a pluralistic design. Journal of Psychiatric and Mental Health Nursing, 9, 325-337

Duxbury, J., \& Whittington, R. (2005). Causes and management of patient aggression and violence: staff and patient perspectives. Journal of Advanced Nursing, 50 (5), 469-478

Eakman, A. M (2011). Convergent validity of the Engagement in Meaningful Activities Survey in a college sample. OTJR: Occupation, Participation and Health, 30, 23-32

Eakman, A. M. (2014). A subjectively based definition of life balance using personal meaning in occupation. Journal of Occupational Science. 1 - 20

Eakman, A. M. (2015). Meaning, sense-making and spirituality. In C. H. Christiansen, C. 
Eakman, A. M., Carlson, M.E., \& Clark, F. A. (2010). Factor structure, reliability and convergent validity of the Engagement in Meaningful Activities Survey for older adults. OTJR: Occupation, Participation and Health, 30, 111-121

Exworthy, T., \& Gunn, J (2003). Taking another tilt at high secure hospitals: The Tilt Report and its consequences for secure psychiatric services. British Journal of Psychiatry, 182, $469-471$

Fallon, P., Bluglass, R., Edwards, B., \& Daniels, G (1999) Report of the Committee of Inquiry into the Personality Disorder Unit, Ashworth Special Hospital

Finnema, E.J., Dassen, T., \& Halfens, R. (1994). Aggression in psychiatry: a qualitative study focusing on the characterisation and perception of patient aggression by nurses working on psychiatric wards. Journal of Advanced Nursing, 19, 1088-1095

Fortune, C., Ward, T., and Polaschek, D.L.L. (2014). The Good Lives Model and therapeutic environments in forensic settings. Therapeutic Communities: The International Journal of Therapeutic Communities, 3, 95-104

Francis, R., Daniels, G., \& Baird, J. (2009). Independent inquiry into the care and treatment of Peter Bryan and Richard Loudwell: A report for NHS London.

Gadon, L., Johnstone, L., \& Cooke (2006) Situational variables and institutional violence: A systematic review of the literature. Clinical Psychology Review, 26, 515-534

Godelieve de Vries, M., Brazil, I.A., Tonkin, M., \& Bulten, B. H. (2016). Ward climate within a high secure forensic psychiatric hospital: Perception of patients and nursing staff and the role of patient characteristics. Archives of Psychiatric Nursing, 30, 342-349

Goldberg, B., Brintnell, E. S., \& Goldberg, J. (2002). The relationship between engagement in meaningful activities and quality of life in persons disabled by mental illness. Occupational Therapy in Mental Health, 18 (2), 17-44 
Hallett, N., Huber, J. W., \& Dickens, G. L. (2014). Violence prevention in inpatient psychiatric settings: Systematic review of studies about the perceptions of care staff and patients. Aggression and Violent Behaviour, 19, 502-514

Hodge, J. E., \& Renwick, S. J. (2002). Motivating mentally disordered offenders. In M. McMurran (Ed.), Motivating offenders to change: A guide to enhancing engagement in therapy (pp. 221-234). Hoboken, NY, USA: Wiley

Huesmann, L.R. (1998). The role of social information processing and cognitive schema in the acquisition and maintenance of habitual aggressive behaviour. In R.G. Green and E. Donnerstein (eds), Human Aggression: Theories, Research, Implications for Social Policy. San Diego, CA: Academic Press, 73 - 109.

Ireland, J. L. \& Rowley, J. (2007). Sectioned offenders presenting with enduring mental illness: A study exploring behaviours indicative of bullying. Aggressive Behaviour, 33, 377-388 Irwin, J., \& Cressey, D.R. (1962). Thieves, convicts and inmate culture. Social Problems, $10,142-155$

Jackson, J., Tyler, T.R., Bradford, B., Taylor, D., \& Shiner, M. (2010). Legitimacy and procedural justice in prisons. Prison Service Journal, 191, 4-10

Johnson, B., Martin, M. L., Guha, M., \& Montgomery, P. (1997) The experience of thought disordered individuals preceding an aggressive incident. Journal of Psychiatric and Mental Health Nursing, 4, 213-220

Kiesler, D. J. (1987). Manual for the Impact Message Inventory. Palo Alto, CA: Consulting Psychologists Press, Inc.

Kiesler, D. J. \& Schmidt, J. A. (2006) The impact message inventory-circumplex (IMI_C) manual 
Lillie, R. (2007). Getting clients to hear: Applying principles and techniques of Kiesler's interpersonal communication therapy to assessment feedback. Psychology and Psychotherapy: Theory, Research and Practice, 80, 151-163

Meehan, T., McIntosh, W., Bergen, H. (2006). Aggressive behaviour in the high-secure forensic setting: the perceptions of patients. Journal of Psychiatric and Mental Health Nursing, $13,19-25$

Morris, R.G., Carriga, M., Diamond, B., Piquero, N.L., \& Piquero, A.R. (2012). Does prison strain lead to prison misbehaviour? An application of general strain theory to inmate misconduct. Journal of Criminal Justice, 40 (3), 194 - 201

Muir-Cochrane, E. C., Baird, J., McMann, T. V. (2015). Nurses' experiences of restraint and seclusion use in short-stay acute old age psychiatry inpatient units: a qualitative study. Journal of Psychiatric and Mental Health Nursing, 22, 109-115

Olver, J., Love, M., Daniel, J., Norman, T., \& Nicholls, D. (2009). The impact of a changed environment on arousal levels of patients in a secure extended rehabilitation facility. Australasian Psychiatry, 17 (3), 207-211

Poole, E.D., \& Regoli, R.M. (1983). Violence in juvenile institutions. Criminology, 21, $213-232$

Powell, G., Caan, W., \& Crowe, M. (1994). What events precede violent incidents in psychiatric hospitals? British Journal of Psychiatry, 165, 107 - 112.

Pulsford, D., Crumpton, A., Baker, A., Wilkins, T., Wright, K., \& Duxbury, J. (2013) Aggression in a high secure hospital: staff and patient attitudes. Journal of Psychiatric and Mental Health Nursing, 20, 296-304

Reisig, M.D., \& Mesko, G. (2009) Procedural justice, legitimacy and prisoner misconduct. Psychology, Crime and Law, 15, 41-59 
Rocheleau, A.M. (2013). An empirical exploration of the "pains of imprisonment" and the level of prison misconduct and violence. Criminal Justice Review, 38 (3), 354-374

Ryan, R.M., Deci, E.L, \& Grolnick, W.S. (1995). Autonomy, relatedness, and the self: Their relation to development and psychopathology. In D. Cicchetti \& D.J. Cohen (Eds.), Developmental psychopathology, Vol. 1: Theory and methods (pp. 618-655).Oxford: John Wiley

Schalast, N., Redies, M., Collins, M., Stacey, J., \& Howells, K. (2008). EssenCES, a short questionnaire for assessing the social climate of forensic psychiatric wards. Criminal Behaviour and Mental Health, 18, 49-58

Soares, J. J. F., Lawoko, S., Nolan, P. (2000). The nature, extent and determinants of violence against psychiatric personnel. Work and Stress, 14 (2), 105-120

Steiner, B., \& Wooldredge, J. (2009). Inmate versus environmental effects on prison rule violations. Criminal Justice and Behavior, 438-456

Stewart, D., \& Bowers, L. (2013) Inpatient verbal aggression: content, targets and patient characteristics. Journal of Psychiatric and Mental Health Nursing, 20, 236-243

Stone, T., McMillan, M., Hazelton, M., \& Clayton, E. H. (2011). Wounding words: swearing and verbal aggression in an inpatient setting. Perspectives in Psychiatric Care, 47, 194203

Sykes, G.M. (1958). The society of captives. Princeton, NJ: Princeton University Press.

Thomas, C.W., \& Foster, S.C. (1973). The importation model perspective on inmate social roles: An empirical test. The Sociological Quarterly, 14, 226-234

Thomas, J., \& Harden, A. (2008). Methods for the thematic synthesis of qualitative research in systematic reviews. BMC Medical Research Methodology, 8(45)

Tighe, J., \& Gudjonsson, G. H. (2012). See, Think, Act scale: preliminary development and validation of a measure of relational security in medium and low secure units. The Journal of Forensic Psychiatry and Psychology, 23 (2), 184-199 
Tilt, R., Perry, B., \& Martin, C (2000). Report of the Review of Security at the High Security Hospitals. London: Department of Health

Tyler, T.R. (2006). 'Legitimacy and Legitimation'. Annual Review of Psychology, 57, 375400

Tyler, T.R., \& Fagan, J. (2008). Legitimacy and cooperation: Why do people help the police fight crime in their communities? Ohio State Journal of Criminal Law, 6, 231-275

Uppal, G., \& McMurran, M (2009) Recorded incidents in a high-secure hospital: A descriptive analysis. Criminal Behaviour and Mental Health, 19, 265-276. Urheim, R., Rypdal, K., Palmstierna, T., \& Mykletun, A. (2011). Patient autonomy versus risk management: A case study of change in a high security forensic psychiatric ward. International Journal of Forensic Mental Health, 10 (1), 41-51

van der Helm, P., Stams, G., van Genabeek, M., \& van der Laan, P. (2012) Group climate, personality, and self-reported aggression in incarcerated male youth. The Journal of Forensic Psychiatry and Psychology, 23 (1), 23-39

Virtanen, M., Vahtera, J., Batty, G. D., Tuisku, K., Pentti, J., Oksanen, T., Salo, P., Ahola, K., Klvlmaki, M. (2011). Overcrowding in psychiatric wards and physical assaults on staff: datalinked longitudinal study. The British Journal of Psychiatry, 198, 149-155

Walters, G.D., \& Crawford, G. (2013). In and out of prison: Do importation factors predict all forms of misconduct or just the more serious ones? Journal of Criminal Justice, 41, 407-413

Ward, T. and Gannon, T. A. (2006). Rehabilitation, etiology and self-regulation: the comprehensive good lives model of treatment for sexual offenders. Aggression and Violent Behaviour, 11 (1), 77-94

Willems, A. P. A. M. , Embregts, P. J. C. M. , Stams, G. J. J. M. , \& Moonen, X. M. H. (2010). The relation between intrapersonal and interpersonal staff behaviour towards clients with 
ID and challenging behaviour: A validation study of the Staff-Client Interactive Behaviour Inventory. Journal of Intellectual Disability Research, 54, 40-51.

Williamson, R., Lauricella, K., Browning, A., Tierney, E., Chen, J., Joseph, S., Sharrock, J., Trauer, T., \& Hamilton, B. (2013). Patient factors associated with incidents of aggression in a general inpatient setting. Journal of Clinical Nursing, 1144-1152

Wortley, R. (2002). Situational prison control: Crime prevention in correctional institutions. Cambridge: Cambridge University Press. 